\title{
Hippocratic thought: Its relationship to and between Andrew Taylor Still and Sir William Osler
}

\author{
ROBERT E. SUTER, MSC
}

In recent years, observers of American medical practice have noted a convergence of beliefs in many areas between osteopathic and allopathic schools of thought. This paper proposes an historical explanation for this convergence by examining the lives and teachings of the two physicians who had the greatest influence on their respective schools at the turn of the century. An extensive review is made of the biographical similarities and parallel therapeutic approaches between Sir William Osler and Andrew Taylor Still. The relevance of Hippocratic writings to their beliefs is then explored. The influence of Hippocrates on Osler is well-known, but this paper documents that the similarities between many of Still's concepts, including manipulation, and Hippocratic passages are much more extensive than previously described. It is theorized that AT Still may have been influenced by Hippocratic work during his development of osteopathic medicine. The existence of these extensive similarities, therefore, arguably provides evidence for a common origin of thought in many areas, and correspondingly for a continued, if belated, return to the Hippocratic tradition by both American schools of medicine.

While the public may view American medicine as a homogeneous system, there always has been significant diversity in the science and art of medicine. In the United States today, two schools of medi- cine-the majority, or allopathic, school and the minority, or osteopathic, school-predominate.

See related editorial on $p 1204$.

Over the years, there has been considerable convergence of thought between the schools. First, the osteopathic profession accepted the advances in pharmacology that defined 20 th century drug use. Second, more recently, holistic medicine, biomechanics, and physical medicine have become accepted and popular approaches within allopathic medicine.

What has been lacking in this almost subliminal realization has been a rational explanation of why this convergence of ideas came about. On both sides, the assertion has been that the other school has come to see the value of "their" system. Although this cannot be dismissed completely, historical evidence points to a more logical model. The historical explanation centers on the last years of the 19th and the early years of the 20th centuries, and on the two physicians of that time, Sir William Osler and Andrew Taylor Still, who generally are accepted as having the greatest influence on their respective schools.

As early as the turn of the century, other authors ${ }^{1,2(\mathrm{PP} 66,72)}$ made superficial comparisons between Osler's and Still's therapeutic philosophies. This paper is a more extensive review of the similarities between these two great physicians. It also offers what I believe to be an original theory as to why many of their teachings are so alike, that is, that both were influenced to adopt a Hippocratic approach to medicine. Further, I hope that demonstration of these shared traditions will promote further understanding and cooperation between the two American schools of medicine. 


\section{Biographic events}

When comparing men, the logical place to start is with biographic information. William Osler was born on July 12, 1849. His father was an Anglican clergyman assigned to the Canadian frontier. ${ }^{3(\mathrm{PP} 2-5)}$ A.T. Still had been born more than 20 years earlier, on Aug 6, 1828. During his youth, his father, a Methodist preacher and physician, came west to bring religion to the American frontier. ${ }^{2(\mathrm{P} 1)}$ Making the best use of their wilderness surroundings, both men were enthusiastic naturalists in their boyhood. 3(P21),4(PP34-50)

Despite the rigors of frontier life, Still had a nearly continuous formal education until the age of 20. ${ }^{2(\mathrm{P} 2)}$ Then in Kansas, with aspirations of becoming a physician but hundreds of miles from the nearest medical school, Andrew, in the custom of the early and middle 19 th century, "read medicine" for three years and served an apprenticeship under his father. ${ }^{2(\mathrm{P} 4)}$ In 1854 he was listed on the roll of licensed MDs, and for the next 20 years he maintained a traditional allopathic practice. During this period he was also elected to the Kansas State Legislature on the Abolitionist ticket (1857), and he served as a surgeon in the Union Army in the Civil War (1861 to 1864), holding the rank of Major at discharge. 2(PP3-5)

During the time Still was performing his Civil War service, Osler was finishing his preparatory education. After one year at Trinity College (1867 to 1868 ), he took advantage of the relatively accessible formal medical education and training and began his studies in Toronto in 1868. He later (1870 to 1872) studied at McGill University in Montreal, which had been established by Edinburgh graduates and was probably the finest medical school on the continent at that time. ${ }^{3(\mathrm{P} 7)}$

Osler particularly was interested in anatomy and was described by others as "always dissecting."3(P58) Interestingly enough, during this same period, Still also was heavily engaged in dissection as part of his "restudy of medicine" (1865 to 1874), an in-depth investigation he began following the death of most of his family during an outbreak of spinal meningitis. ${ }^{2(\mathrm{P} 7)}$

The realities and commitments of middle age and a family in the developing frontier limited Still's ability to study beyond the published medical information that found its way into the rural midwest. In contrast, Osler belonged to a generation in which "study abroad was the natural goal of every newly fledged Canadian physician."3(P86) Consequently he traveled to Europe and studied in London, Dublin, Glasgow, Edinburgh, Vienna, and Berlin under some of the greatest men in medicine and science at the "dawn of the most impor- tant period of medicine," which finally had awakened to the importance of experimentation and truly scientific observation. ${ }^{3(\mathrm{P} 92)}$

Following his European education, Osler returned to Canada, where after a very short period as a rural general practitioner he began his career in academic medicine with a teaching post at McGill University in late 1874. Quickly rising to the rank of full professor, he stayed at McGill for the next 10 years, during which time he developed an excellent reputation within the medical profession. ${ }^{3(\mathrm{PP} 120-123}$

Back in Kansas, Still's complete "restudy" of medicine was coming to an end about the same time that Osler returned from Europe. This effort resulted in 1874 in the formulation of a medical philosophy that he was to call osteopathy. ${ }^{2(\mathrm{PP} 106-108} \mathrm{De}-$ spite the fact that he initially applied his new philosophy and therapies in conjunction with accepted allopathic remedies, his theories generated considerable opposition from his local colleagues. As a result of this opposition, his petition to teach and explain his findings at Baker University in Baldwin, Kan, was rejected by the regents, a decision that was particularly painful because he and his family had donated the land for and had helped to build that institution. ${ }^{4(P P 110-112)}$

Believing that this failure signaled that he would never be permitted to explain his theories within allopathic medicine, and finding the criticism in Kansas particularly intense, Still became an itinerant physician and traveled throughout Missouri before finally settling in Kirksville in 1887.4(P129) $\mathrm{He}$ gradually reduced the use of drugs as part of his therapeutic regimen, and by 1884, the year Osler left McGill University, it is evident that Still had rejected their use altogether. ${ }^{2(P P 17-18)}$

Arriving at the University of Pennsylvania in the autumn of 1884 as the Chair of Medicine, Osler continued to expand his fame. Despite the fact that it was probably the best medical school in the United States, and only the second to require a three-year course with examinations for graduation, there were no laboratories, microscopes, or clinical studies prior to his arrival. ${ }^{3(\mathrm{PP} 236,284)} \mathrm{His}$ stay in Philadelphia was to be relatively short, however, because he was excited by the ambitious plans for The Johns Hopkins School of Medicine, and he accepted the Chair of Medicine there in 1889. ${ }^{3(\mathrm{P} 297)}$ Here Osler wrote The Principles and Practice of Medicine (1892), ${ }^{5}$ which enhanced his already formidable reputation, although most other physicians did not subscribe to his therapeutic views. ${ }^{3(\mathrm{P} 359)}$

At the same time that Osler's views were being disseminated by publication of his text, Still also made the decision to promulgate his theories and 
observations by opening his own school of medicine. In early 1892 , he began the process of establishing a school in response to numerous requests. This decision was sealed, however, by a chance meeting with William Smith, MD, MRCP, an Edinburgh graduate with seven years of formal medical education. After hearing Still's theories and observing his practice, Smith was convinced of the importance of Still's work and agreed to help him establish a school. ${ }^{2(\mathrm{P} 19)}$ This institution, which originally was called the American School of Osteopathy, was in 1892 granted a charter by the state of Missouri that allowed it to grant the MD degree. ${ }^{6(\mathrm{P} 8)}$ Disregarding the advice of others, however, Still insisted that the school grant a DO degree to distinguish its graduates from those of allopathic programs. ${ }^{2(\mathrm{P} 35)}$ Declared open to "Negroes and women," the first class started in 1892 with 18 students, including three women, with Drs. Still and Smith as the primary instructors. ${ }^{2\left({ }^{(19)}\right.}$ By an improbable coincidence, medical education at Johns Hopkins began in 1893 with an entering class of 18 , which also included three women. ${ }^{3(\mathrm{P} 389)}$

In Baltimore with those first students, Osler was busily writing subsequent editions of his text while setting an example of medical education and practice that was destined to have lasting influence. Looking toward Europe for his next assignment as early as 1900 , he received the call in 1904 and became the Regis Professor of Medicine at Oxford University. ${ }^{3(\mathrm{PP} 518,626)}$

Just as Osler's text is considered a landmark work by medical historians, Still's books are thought to be classics by those interested in the history of osteopathic medicine. Still published three major works, Autobiography of Andrew T. Still (1897), ${ }^{4}$ Philosophy of Osteopathy (1899), ${ }^{7}$ and Osteopathy Research and Practice (1910). ${ }^{8}$

As his text gained in popularity, Osler began to leave the scientific advances of the 20th century to the younger generation, ${ }^{3(\mathrm{P} 323)}$ At the same time, Still, 21 years his senior, did likewise as he realized that his school was on a firm foundation. While clinical observation was Still's personal strength, he welcomed osteopathic research and experimentation, which began in 1898 on laboratory animals and which has continued since under strict scientific standards. ${ }^{6(\mathrm{P} 16)}$ Still kept his personal association with the school, of course, but for the most part he left the teaching to others until his death in 1917 at the age of $89 .^{6(\mathrm{P} 19)}$

Although World War I brought Osler a commission in the British Army Medical Corps, his involvement in medicine became more and more advocacy and politics. ${ }^{9(\mathrm{PP} 426-619,621-686)}$ Although his mother had lived to be older than 100 years, Osler died in 1919 at the age of 70 following a long illness. ${ }^{9(\mathbf{P} 684)}$

The biographic similarities between Osler and Still may help to explain some of their personal attributes as well. Both had a frontier boyhood and a fascination with the wonders of nature, which explains their later dedication to the subject of anatomy*. Both discounted their own intelligence, with Osler stating that he started with "just an ordinary everyday stock of brains," $3(\mathrm{P} 81)$ and Still describing himself as "but an ignorant man who spent all my life in the West."4(P147)

However, Still's sudden celebrity during the 1890 s fueled for a short period a tendency to make aggrandizing statements that might be considered exaggerated generalizations, especially in his autobiography. ${ }_{4}^{4(\mathrm{PP} 46,50,86,114)}$ However, there is evidence that in retrospect he realized this, and he explained his statements accordingly. ${ }^{4(\mathrm{P} 243), 8(\mathrm{PPVI}, \mathrm{VII}, 3)}$

Other similarities beg comparison. Both men were described by associates as teetotalers, although Osler would accept a social drink from time to time. ${ }^{3(\mathrm{P} 394)}$ They shared a strong belief in $\mathrm{God}^{4(\mathrm{PP} 101,240,323)}$ and, although Still was more public in this regard, Osler cited the Bible frequently in his text. ${ }^{10}$ Predictably then, they both were fascinated with death as an abstract concept. $^{3(\mathrm{P} 294) 4(\mathrm{P} 245)}$ In addition, both physicians were liberal for their day in their tolerance and support of those who were subject to social or professional oppression. ${ }^{\dagger}$ Finally, while Still's eccentricities are often cited, Osler's continued devotion to pranks and practical jokes throughout his life is surprising for someone of his stature. ${ }^{3(\mathrm{P} 24-46), 12}$

\section{Similarities in medical thought}

Whether these background similarities had any influence in orienting Osler and Still toward the adoption of often comparable thoughts about medical practice is open to debate. However, it appears that their similarities are far more extensive than have been previously catalogued.

Even those who are only casually familiar with the history of osteopathic medicine correctly assume that Still became a "drugless healer," although they may not know why. Only persons who study Osler in depth, however, realize that he frequently was criticized as a "therapeutic nihilist" by contemporaries for his failure to use drugs in most diseases. ${ }^{3(\mathrm{P} 165,267,268)}$ His distaste for drugs in most situations even led him to attempt unorthodox

\footnotetext{
References 3(pp21,58,504), 4(pp34-50,145,178), 8( $p v)$.

$\dagger$ References 3(pp255,307,373,546,587), 4(pp175,370), 9( pp222, $223,655), 11$
} 
alternatives, such as acupuncture. ${ }^{3(\mathrm{P} 177)}$ Osler, like Still, rejected outright the polypharmacy that characterized 19 th century medical practice. He usually refrained from the use of individual medications for the same reason that Still did-they were toxic and ineffective, and they hindered the body's natural tendency to heal itself.* These beliefs became manifest early in Osler's career, as evidenced by the story of his taking charge of his first ward at Montreal General Hospital. Immediately upon assuming control, he ordered that the patients have nearly all of their medications stopped. What happened next is recounted in a passage that sounds curiously similar to descriptions of Still's clinics in Kirksville: "To the astonishment of everyone, the chronic beds, instead of being emptied by disaster, were emptied rapidly through recovery." $3(\mathrm{P} 172)$

This tendency not to use drugs actually grew stronger during Osler's career. As the Regis Professor of Medicine at Oxford University in 1916, he counseled physicians to "shunt the whole pharmacopoeia except opium."3(P671) These feelings after 40 years of practice correlate fairly well with Still's beliefs at the same age. While Still made it clear that he personally had "forever" renounced the use of drugs in his practice, he did leave the door open for his students if pharmacy was put on a scientific basis, and in 1910 he made a statement very similar to Osler's later pronouncement: “...the world would be just as well off or even better off (with very slight exception) had there never been a system of drug medication."8(PVI)

Still's belief that anatomy was the only true science of his day and his development of a system that made extensive use of palpation in diagnosis made his eventual decision to limit his practice to surgery and manipulation quite understandable. Surprisingly enough, however, Osler, in his first text, warmly embraced the use of manual procedures in many conditions, and he also reported on characteristic musculoskeletal findings associated with some visceral diseases. ${ }^{5(\mathrm{P} 94)}$ Conditions that he believed benefited from manual therapy included pernicious anemia, constipation, gout, rheumatoid arthritis, rickets, intestinal obstruction, chronic rheumatism, diphtheria, and neuritis. ${ }^{\dagger}$ For example, on the subject of neuritis, Osler stated:

\footnotetext{
*References 3(pp171,172,324,564), 4(pp175,184,191,196,240, $242,266,285,286,326,384,5$ ( $p p 33,36,37,76,98,100,278,320$,

$375,420,422,431,746), 9(p p 180,222,671)$.

†Reference 5(pp110,286,294,312,420,422,696,781).
}

Gentle friction of the muscles may be applied from the onset and in later stages, when atrophy is marked and the pains have lessened, massage is probably the most reliable means at our command. Contractures may be gradually overcome by passive movements and extension. Often, with the most extreme deformity from contracture recovery is, in time, still possible. ${ }^{5(\mathrm{P} 781)}$

Of course, this practice had much in common with the symptomatic portions of the techniques used in Kirksville, although Still did not limit his treatment to just the area involved. Even though Osler did not extend his manual therapy recommendations past symptomatic care, he did visualize disease and recovery beyond their local effects. He observed a mind and body interaction, and he offered a nonjudgmental explanation for faith cures that was consistent with his belief that there was nothing at all wrong with them. ${ }^{*}$ Still also viewed the brain as having a critical role in health and disease, although he proposed a purely physiologic explanation 4(PP149,223,224); perhaps he was sensitive to the charges by his detractors that he was a faith healer.

Finally, both Osler and Still had an orientation toward preventive medicine and the importance of heredity in disease. From his European experiences, Osler stressed the importance of sanitation in the prevention of epidemics and Still held similar views. Both also taught the importance of heredity as a factor in an individual's disease process, Still adding the thought that, as a result of war between nations, mankind was moving in opposition to Darwin's theories, because the fittest went to war and were often killed, while the weak were exempt from service and thereby survived to

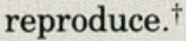

\section{Differences in medical opinion}

I have reviewed some of the key areas in which William Osler and Andrew Taylor Still were in agreement and the retrospective value of their teachings in these areas. Perhaps as interesting, however, were their inaccuracies. While Osler was a world-class pathologist, he was not on the cutting edge of physiology. Although he had direct contact with Pasteur in Europe, Osler was not an early supporter and clung to the theory of spontaneous generation until at least $1882 .{ }^{3(\mathrm{PP} 119,164,184,190)} \mathrm{Also}$, like others, he did not grasp the significance of Lister's work during his training years, during which time Lister was encountering stiff opposition. ${ }^{3(\mathrm{P} 111,167)}$

\footnotetext{
* References 3(pp546,637), 9(pp181,222).

† References 3(pp194,195,370,432), 7(pp204,205).
} 

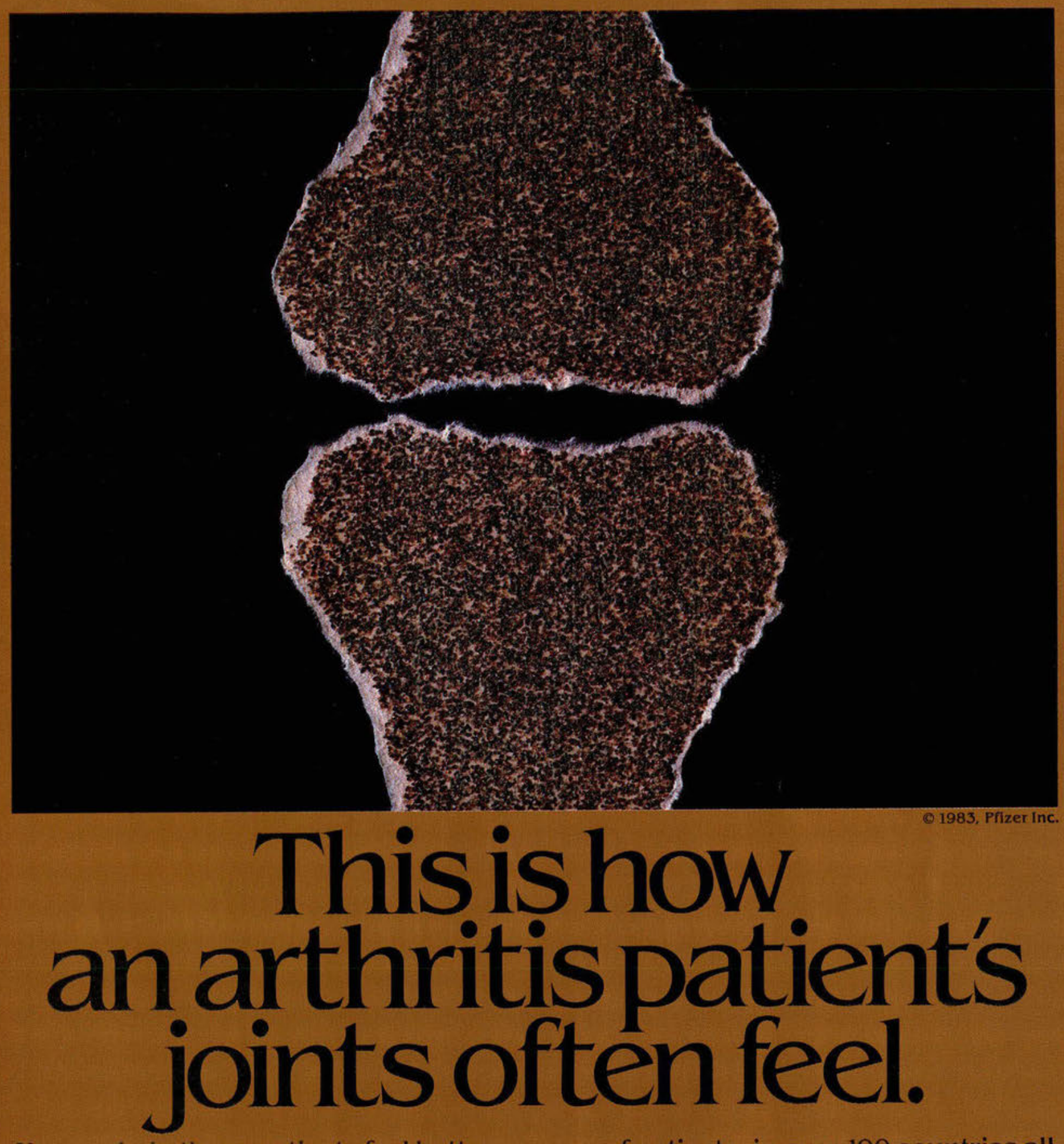

You can help these patients feel better with one-a-day FELDENE" (piroxicam).

For good reasons:

- it's effective-proven relief of the pain

and inflammation of rheumatoid

arthritis and osteoarthritis ${ }^{\prime}$ in millions

of patients, in over 100 countries all around the world.

- it's efficient-once daily, 20-mg dose provides round-the-clock relief, improves compliance and remains effective during long-term therapy.

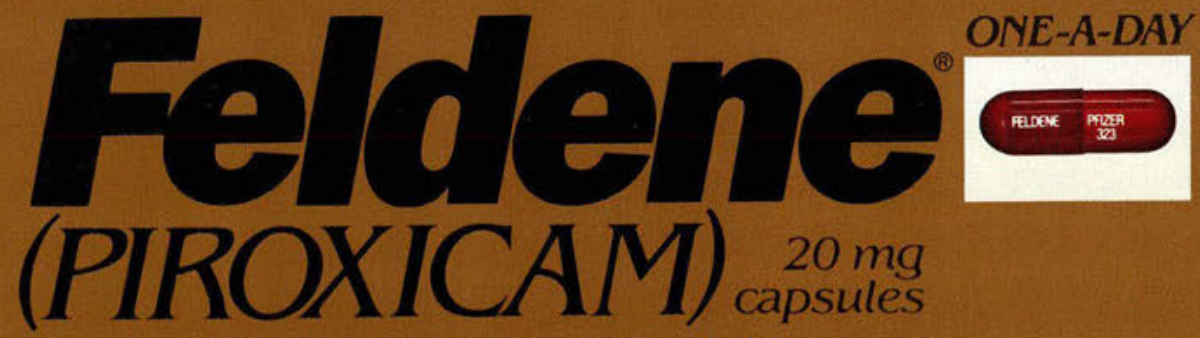

Please see FELDENE (piroxicam) brief summary on the following page. 


\section{Feldene (PIROXICAM) $)_{\text {apomeg }}^{20 \times 9}$}

\section{Prescribe one $20 \mathrm{mg}$ capsule daily for convenience and compliance}

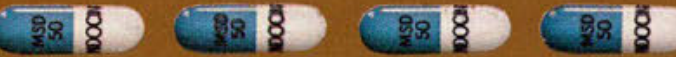

\section{0}

Indicates maximum dosage for osteoarthritis and rheumatoid arthritis for the antiarthritic agents shown. Consult manulacturers' prescribing information

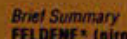

FELDENE* (piroxicam) Capsules

CONIRAimoicaniOWS: FELDENE (pircocicam) should not be used in patients who have previously exhibited hypersensitivity

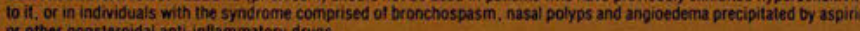
or other nonsteroidal anti-inliammatory drug

WARMIWGS: Peptic ulceration, perforation and $G$ I. bleeding-sometimes severe, and, in some instances latal-have been reported with patients receiving FELLENE. If FELDENE must be given to patients with
tract disease, the patient should be under close supervision isee ADVERSE REACTIONS

tract disease, the patient snouid be under close supervision (see ADVERSE REACriONS).
PRECAUnONS: Renal Effects: As with other nonsteroidal anti-inflammatory drugs. long-term administration of piroxicam to animals has resuited in renal papiliary necrosis and other abnormal fenal pathology. In humans, there have been reports of acule interstitial nephritis with hematuria, proteinuria, and occasionally, nephrotic syndroms.

A second form of renal toxicity has been seen in patients with prerenal conditions leading to a reduction in renal bloor now or blood volume; where the renal prostaglandins have a supportive role in the maintenance of renal periusion. In thes. patients adniaisitation of an hsaiu may cause a cose-oependent reduction in prostaglandin formation and may precipitate overt renal decompensation. Patients at greatest nisk of this reaction are those with impaired renal function, heart tailure
liver oystunction, those taking diutetics. and the eloerly.

brectius of exiensive renai excretion of piroxicam and its biotranstormation products (less than $5 \%$ of the daily dos: should be carefulily monitorec

Althoigh other nonsteroital anti-inflammatory druns do not have the sume direct eftect on plateiets that aspirin does. all drugs inhibring prostaglandin biosynthesis do interfere with platelet function to some depree

Because of reports of adverse eye findings with nonsteroidal ant-inflammatory agents, it is recommended that patients who develop visual complaints during treatment with FELDENE have ophthaimic evaluation.

As with other nonsteroidal anti-inflammatory drugs, bordertine elevations of one ot more fiver tests may occur in up to 15* of patients. A patient with symptoms and or signs sugpesting liver dystunction, or in whom abnormal tiver tests havi occurred, should be evaluated for evidence of the development of more severe hepatic reaction while on therapy with

Severe hepatic reactions, including jaundice and cases of tatal hepatitis have been reported with fEL OENE. Aithough such reactions are rare, if abnormal iver lests persist or worsen, if clinical signs and symptoms consistent with liver dis. ease develop, or it systemic man
also ADVERSE REACTIONS

Although at the recommended dose of $20 \mathrm{mg} / d a y$ of FEL.DENE increased lecal blood loss due to gastrointestinaf irritation did not occur. in about $4 \%$ of the patients treated with FELDENE alone or concomitantly with aspirin. reductions in he moglobin and hematocrit values were observeo

Peripheral edema has been observed in approxinately $2 \%$ of the patients treateo with FELDENE. Therefore, FELDENE should be used with caution in patients with heart tailure, hypertension or other conditions predisposing to fluid tetention A combination of dermatological and/or allergic signs and symptoms suggestive of serum sickness have occasionality occurred in conjunction with the use of FELDENE. These include arthralgias, prurtivs, fever, tatigue, and rash includiof vesiculo bullous reactions and exdoliative dermatit

OAUG IWTERACTIONS: Interactions with coumarin-type anticoagulants have been reported with FEL DENE since marketing Therefore, physicians should closely monitor patients for a change in dosage requirements when administering FELOENE patients on coumarin-type anticoaguiants and other highty protein-bound orugs

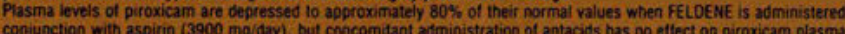
in conj:

Nonsteroidal anti-inflammatory agents, includiog FELOENE, nave been reported to increase steady state plasma lithium levels. It is recominended that plasma lithium levels be monitored when initiating. adjusting and discontinuing fELOENE Carcinogenesis, Chronic Animal Toxicity and impairment of fertility: Subacute and chronic toxicity studies have bee: carried out in rats. mice, dogs, and monkey

The pathology most often seen was that characteristically associated with the animal toxicology of anti-inflammatory agents: renal papillary neciosis (see PRECAUTIONS) and gastrointestinal lesions

in classical studies in laboratory animals, piroxicam did not show any teratogenic potential

Reproductive studies revealed no impairm

Prepnancy and Mursing Mothers: Like other drugs which inhibit the 5ynthesis and release of prostaglandins. pitoxicam

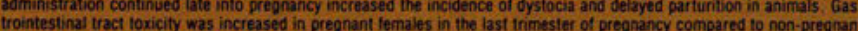
trointestinas tract toxicity was increased in pregnant

FELDENE is not recommended for use in nursing mothers or in pregnant wornen because of the animal findings and since satety for such use has not been established in trumans

Use in Chilldrea: Dosage recommendations and indications for use in children have not been established

ADVERSE REACTOW: Gastrointestinal symptoms are the most prominent side effects, occurring in aporoximately $20 \%$ of the patients, which in most instances did not intertere with the course of therapy. Of the patients experiencing gastro
intestinal side effects, approximately $5 \%$ discontinued therapy with an overali incidence of peptic ulceration of about $1 \%$.
Adverse reactions are listed below by body system for all patients in clinical trials with fELOENE (piroxicam) at coses $120 \mathrm{mgda}$ incidence Greater Than 1\%: The following adverse reactions occurred more trequently than 1 in 100

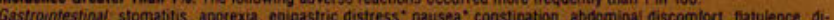
thea. abdominal pain indigestion Hematologicat decreases in hemoglobin" and hematocrit" (see PRECAUTIONS). anemia, leucopenia, eosinophilis Dermatologic pruritus. rast

Central Nervous System: diziness, somnolence, vertio

Urogenitat: BUN and creatinine elevations (see PRECAUTIONS)

Body as a Whole headache. malaise

Special Senses: tinnitus

Cardiovascular Riespiratory: edema (see PRECAUTIONS)

Reactions occurning in $3 \% 109 \%$ of patients treated with FELOENE

Reactions occurring in $1 \%$ to $3 \%$ of patients are unmarke

Incidence Less Than 1\% (Causal Relationship Probable): The following adverse reactions occurred iess trequently than in 100 . The probability exists that there is a causat relationship between FELDENE and these reaction

Gastrointestinal: liver function abnormalities, jaundice, nepatitis (see Phecauv.

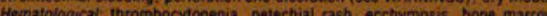

tepression including aplastic anemi.

作 mai necroilysis, Stevens vohnson syndrome, vesiculo bullous reactions. Dhotoallergic skin teactions

Central Nervous System depression. insomnia, nervousnes:

Urogenital hematuria. proteinuria, interstitial nephritis; renal fallure, hypertalemia, glomerultis, papiliary nectosis.

ephrotic syndrome (see PRECAUTIONS)
Body as a Whole: pain (colic), tever, flu-like syndrome (see PAECAUTIONS)

Special Senses swollen eyes. blutred vision, eye irritation

Cardiovascutar Respiratory bypertension, worsening of congestive heart tailute (see PRECAUTIONS), exacerbation of ging

Metabolic hypogiycemia, hyperglycemia, weight increase, weight decrease

Hypersensitivity anaphylaxis, bronchospasm, urticaria angioedema, vascultis, "serum sickness" (see PRECAUTIONS)

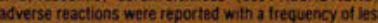
than 1 in 100 , but a causal rela

Vermatologic: onycholysis, loss of hait

Central Nervous Systom: akathisia. hallucinations, mood atterations, oream abnormaities. mental contusion. paresthesias

Crogenital System dysuria

Bocy as a Whole weakness

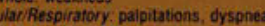

aypersensitivity: positive ANA

Specal Senses bearing inpaiment
OVEADOSAGE: in the event treatment for overdosage is required, the long plasma halt-lite of piroxicam should be consid. ered. The absence of experience with acute overdosage precludes characterization of sequelae and recommendations of specific antidolal efficacy at this time. It is reasonable to assume that the standard measures of gastric evacuation and generai supportive therapy would apply in addition to supportive measures, the use of activated charcoal may effectively reduce the absorption and reabsorption of piroxicam. Experiments in dogs have demonstrated that the use of multipie-dose treatments with activated charcoai could reduce the hali- -ilte of piroxicam elimination from 27 hours (withoul charcoai) to
11 hours and reduce the systemic bioavailabulity of pirroxicam by as much as $37 \%$ when activated charcost is given as late 11 hours and reduce the systemic bioavailability of piroxicam by as much as $37 \%$ when activated charcoast is given as late as 6 hours atter adrministration of piroxican

ADMinistRATION AMU OOSAGE: Rheumatoid Arthritis. Osteoarthitis: It is recomimended that fELDENE therapy be in tiated and maintained at a single daily dose of $20 \mathrm{mg}$. If desired, the daily dose may be divider Move detailed professional inflormation avaliable on request

61982. Pfizer ine

Referonces: 1 Siegmeth $W$. Serum concentrations of proxicarn in relation to its clinical effect in patients with chronic polyarthrilis (trans). Wien Med Wochenschr 130:31-35, 1980.2. Tausch Placebo-controlled study of piroxicam in the tiea) ment of rheumaloid arthritis. Am J Med (report) 72: 18-22. February 16. 1982 
Although Still cannot be argued to have had any great insight in this regard, as a result of his observations of postoperative mortality he did abandon surgery for the period following his break with allopathic medicine until Lister's recommendations were accepted, at which time they were incorporated into his practice.* (There is no evidence of Still's performing surgical procedures between 1874 and 1892 , after which he resumed the practice.) Given the beliefs of the day, it would not be surprising if he had subscribed to spontaneous generation early in his career, but his writings give us no evidence of this.

Still did, however, have what can now be called simplistic views on the chemical transformations of matter within the body. He thought of heat as having an important place in both normal and abnormal physiology, although, unlike the eclectics, he viewed fever as an intermediate effect and not as an independent causative agent. ${ }^{4(\mathrm{PP} 107,150,151)} \mathrm{Ex}$ plaining a theoretical mechanism of heat generation within the body led Still to one of his most important generalizations in physiology, which was only later supported by research. He theorized that the nervous system is electrical in nature, with elec-. trical potentials generated with the brain and transmitted via the nerves to control the whole body, including the vasculature. It is primarily through mediation of the vasculature, Still maintained, that the nervous system can produce some of the characteristic effects that are the body's response to disease. ${ }^{4(108,149,300,310)}$

The general similarities between Osler and Still on the subject of pharmacology as it existed in the late 19th century, as well as Osler's apparent rejection of all drugs except opium late in his life, have been pointed out. It is now known that only a handful of agents available then (quinine, digitalis, salicylates, colchicine, and the opiates) were of potential value, and even these were not used appropriately. While Osler was using moderate doses of drugs in a limited number of conditions, his greatness should not intimidate us from observing retrospectively that even in his relative caution he was often wrong. In his textbook, he argued in favor of strychnine over digitalis in the treatment of congestive heart failure, recommended arsenic in the treatment of pernicious anemia, and lead for hemorrhage of the bowel. ${ }^{5(\mathrm{PP} 37,129,696)}$

Discussing the treatment of chronic rheumatism, Osler wrote that "salicylates are useless,"5(P278) and, on the subject of the mercury-laden drugs popular

\footnotetext{
'Reference 4(pp114-146,168,394,395).
}

at the time, he said, "Fortunately for the patients, a majority of these medicines meet one of the two objectives Hippocrates says the physician should always have in view-they do no harm."

While in fairness it should be pointed out that not all of Still's conjectures have stood the test of time, on this subject he warned of the dangerous effects of many remedies and taught his students that mercury-containing drugs cause loosening of the teeth ${ }^{4(\mathrm{P} 184)}$ and that quinine caused other pathologic conditions when used chronically. ${ }_{4}^{4(\mathrm{PP} 285,286)}$

Another surprising finding in Osler's text was his recommendation of bloodletting for the treatment of dyspnea associated with cyanosis, ${ }^{5(\mathrm{P} 680)}$ and, as late as 1912, he was still advocating its use in the management of pneumonia. ${ }^{13(\mathrm{PP} 99,100)}$

On the subject of appendicitis, however, Osler took a more characteristically conservative approach, and, like Still, ${ }^{4(\mathrm{P} 260)}$ he thought that most surgeons were too aggressive in managing this condition; he recommended that the physician wait until the nature of the course of the disease was apparent. ${ }^{13(\mathrm{P} 413)}$

Osler and Still differed, however, in their attitudes toward vaccination, with Osler a strong advocate $^{9(\mathrm{P} 427)}$ and Still an opponent. ${ }^{8(\mathrm{P} 14)}$ Still's opposition to vaccination is curious considering another of his important generalizations about natural immunity, which was expressed by his assertion that the body contains a "whole system [of] drugs in abundance to cure all infirmities"4(P100) and that these substances are transmitted via the blood.

While discovery of the existence of drug receptors and immunoglobins in the body reinforced this theory, its full appreciation has come in the past 25 years with the identification of numerous endocoids, including endorphins, enkephalin, interleukins, and interferon. It is interesting that Still stated that the brain contained it own "opiates, acids and anti-acids" ${ }^{4(\mathrm{P} 219)}$ almost 90 years prior to the isolation of endorphins and over 100 years prior to current research at Johns Hopkins that points toward a neurohumoral role in gastric ulcer formation.

Still theorized that part of the efficacy of manipulation was due to its stimulation of these endogenous drugs, a theory that has found some support in recent years in studies by basic science researchers at osteopathic institutions. ${ }^{14,15}$

\section{The Hippocratic influence}

As previously mentioned, others have made passing mention of similarities between Osler's and Still's medical concepts. No one has attempted to explain these, however, even though there are in- 
dependent theories about the influences on each physician.

While Osler was a pioneer in the field of pathology, many of his attitudes toward therapeutics were attributed to his study of the acient Greeks, and his preferences in this regard often were criticized during his lifetime.*

Previous authors have attributed Still's views to the combined impact of the eclectics, homeopathy, magnetic healing, and, perhaps, a chance encounter with a "bonesetter," (a layperson practicing skills that had been passed down throughout the centuries). ${ }^{2(\mathrm{PP} 7-16)}$ There is no hard evidence, however, that Still was influenced by any of these theories. A problem exists in that his personal library was not catalogued during his lifetime and was divided among his children upon his death. As a result, references relevant to these theories are not a part of the admittedly incomplete reassembled collection of Still's books. ${ }^{2(\mathrm{PP} 153,154) \dagger}$ While this same problem exists with another theory that deserves expression, the similarities to Osler, with his known influences, and a study of many relevant texts had led me to believe that at some point during his restudy of medicine, Still may have read the Francis Adams translation of The Genuine Works of Hippocrates, ${ }^{16}$ which was published in London in 1849.

The cynic might find this theory that Still was heavily influenced by Hippocrates to be predictable, given that others have observed that Hippocrates has been claimed and invoked by nearly all of the leading schools of medicine of later times. ${ }^{17(\mathrm{P} 2)}$ If, however, one discounts the notion that osteopathy came to Still in a flash of inspiration, ${ }^{2(\mathrm{P} 1)}$ the evidence for Hippocratic influence compares quite favorably with that for other theories.

The first issue is the availability of the Hippocratic text to Still. It is doubtful that the Adams work, which was said to be the first complete English language translation, was available in the American Midwest during his initial education. It is probable, however, that it could easily be obtained in later years. Unfortunately, Still did not specifically identify those to whom he compared his theories, although he claimed to have "read all

'References 3(pp63,167,370,511,617), 9(pp53,162,221,254,351, $375,445)$.

This information regarding the status of Still's library remains correct according to telephone conversations with Mrs. Jane Denslow-of the A.T. Still Museum, Still's great-grandson Harold Still, DO, and Ms. Andrea Dzik of the American Osteopathic Association. the authors from Aesculapius to this date" and felt comfortable enough with the conjectures of "the ancient theorists" on the causes of fever to state that he did not agree with them on this subject. ${ }^{7(\mathrm{PP} 180,181)}$ It would seem, however, that as a physician trained in the traditional school, Still at least initially would have had more of a tendency to study "the father of medicine" than the writings of medical reformers.

Given that Still may have had access to the book during his restudy of medicine, its contents should be examined. There are numerous examples of both the strengths and weaknesses of Still's theories within Hippocratic writings.

Transformation of matter in the body between solid, liquid, and gaseous phases, seemingly one of the most curious concepts in Still's books, had a prominent place in Hippocratic writings, with the primary focus of activity considered to be in the lungs.* Still also centered transformation in the lungs, and he tied it to his concept of heat, which he thought was generated by the burning of food, mediated by the heart, and distributed via the blood. ${ }^{\dagger}$ Hippocrates described an identical process, and, again in agreement with what Still was later to say, saw all these concepts as having an important role in health and disease. $\ddagger$

Along this same line, Hippocratic writings gave a prominent place to the movement of fluid humors as a factor in pathophysiology, $\S$ and, while Still had moved away from the humoral theory itself, he did favor the emphasis on fluids that was incorporated into it.ll

More similarities exist. Still's strong belief in distinguishing cause from effect in disease and then directing efforts at the cause while treating the whole body echo Hippocrates' teachings in this regard.** Central to this thought is that disease is independent of the organs or parts affected, ${ }^{18(\mathrm{PP} 26,28,31)}$ a concept Still also espoused. We have already reviewed Osler's and Still's advocacy of the roles of heredity and a mind and body interaction in disease, as well as the importance of natural law. These, too, were Hippocratic beliefs. \# In addition, because the Greeks were interested in magnetism, ${ }^{17(\mathrm{P} 90)}$ it is possible to challenge the theory

\footnotetext{
* References 17(pp50,113), 18(pp13,53).

† References 7(pp28,82,83,92-96,100).

$\doteqdot$ References 16(pp343-346), 18(pp13,14,53).

$\S$ References 16(pp347-359), 17(pp51,54,126, 18(pp13,59).

\| Reference 4(pp108,188,219,224,300,310).

"* References 17(pp29,53,63), 18(pp50,77,20).

\# References 16(pp33,104,297), 17(p13), 18(p38).
} 
that Still was influenced by 19 th century proponents of magnetic healing.

Most Greek physicians were also athletic trainers or were associated with one. ${ }^{17(\mathrm{P} 120)}$ This, of course, could be expected to have given them a special appreciation of the musculoskeletal system, which is particularly important in reading two of Hippocrates works, "On the Articulations" and "Mochlicus." While traditionally interpreted as standard orthopedics, many comments in these passages have puzzled translators. ${ }^{16(\mathrm{PP} 205-291)}$ Particularly problematic to them were his discussions of and use of the terms subluxation and partial dislocation:

In a word luxation and sub-luxations take place in different degrees, being sometimes greater and sometimes less; and ...the jaw-bone is rarely dislocated but frequently slackened [partially displaced?] in gaping, in the same manner as many other derangements of muscles and tendons arise. ${ }^{16(\mathrm{PP} 223,253)}$

Neither of these passages should perplex anyone who has studied osteopathic or physical medicine, nor should the second quotation surprise the thousands of dentists who are familiar with temporomandibular joint syndrome, because there are great similarities between these writings and present-day descriptions of osteopathic manipulative treatments and physical medicine therapies. The extent of this finding can be realized by reading a paragraph in "On the Articulations," which discusses the role of the seventh cervical vertebra and its structural relationship in inducing and correcting chronic dyspnea:

\footnotetext{
...[the patients] are under this necessity of keeping the neck bent forward at the great vertebra, in order that their head may not hang downward, this therefore occasions great contraction of the pharynx by its inclination inward; for even in those who are erect in stature dyspnoea is induced by this bone inclining inward, until it be restored to its place. ${ }^{16(\mathrm{P} 232)}$
}

These chapters contain much more along these lines than just this passage. Hippocrates made structure-function observations analogous to the ones Still was later to make, and he placed great emphasis on the spine and musculoskeletal system, using bilateral comparative anatomy to find asymmetric prominences. ${ }^{16(\mathrm{PP} 209,210,231,232)}$ This interest may have initially arisen from the vertebral deformities which can result from chronic tuberculosis, which was probably endemic in ancient Greece. Speaking of "gibberosities" above the diaphragm, he stated that these are a sign of "...tubercles in the lungs, for the gibberosities and the distension are produced mostly by such tubercles, with which the neighboring nerves communicate."16(PP232)

While this passage may relate to the lesions of tuberculosis, it is clear from the context of subsequent descriptions that Hippocrates is not limiting his diagnostic spinal findings to these deformities, but rather is considering musculoskeletal asymmetries as well, although the translator, who was admittedly perplexed, used the term "gibberosities" throughout the chapter, occasionally using "subluxation" in its place. After outlining the value in diagnosis, Hippocrates went on to say that "gibberosities" below the diaphragm are the cause of nephritic diseases, bladder affliction, and abscesses. ${ }^{16(\mathrm{PP} 232)}$ The chapter goes on to describe what appears to be techniques of thoracic manipulation and similar procedures for use in adjusting the extremities when "chronic defluxion" at the joints caused other conditions. Particularly important was how these lesions impact on innervation and circulation, ${ }^{16(\mathrm{PP} 241-248)}$ the understanding of which is probably the central aspect of osteopathic theory.

At least two key statements demonstrate that Hippocrates was not just discussing what is considered traditional orthopedics. First, he described patients routinely walking on "partial dislocation of the hip" (translator's words) by musculoskeletal compensation, ${ }^{16(\mathrm{P} 250)}$ something that would be quite a feat for anyone with a classic dislocation. Second, after extensively describing the treatment of spinal "subluxation," Hippocrates specifically distinguished them from displacements of the vertebrae caused by trauma, which he dismissed as "rarely fixable."16(P286)

After dictating the blueprints for a device that closely resembles a manipulative treatment table, Hippocrates described procedures that are not consistent with classical orthopedics but rather closely resembles various osteopathic manipulative approaches. ${ }^{16(\mathrm{PP} 262,263,288,290)}$

There are, of course, differences between Hippocrates' description of manipulation and the manipulative treatments advanced by Still, but they are relatively minor. While Hippocrates stressed the principles of "the axle, the lever, and the wedge,"16(P261) "extension and counter-extension,"16(P265) and "pressure and counter-pressure" $16(\mathrm{P} 278)$ in affecting "reduction and adjustment," $16(\mathrm{P} 282)$ and realized that both the patient's and the physician's body parts could exert these effects, he preferred to use objects such as boards fastened to limbs. A relative exception to this preference concerned mechanical devices used when "the spine protrudes backwards." While he said, "I give great praise to him who first invented this, and any other mechanical contrivance which is according to nature," Hippocrates himself was 
"ashamed to treat in this way," despite his belief that the treatments held potential efficacy. ${ }^{16(\mathrm{PP} 230)}$ $\mathrm{He}$ felt this way because he thought these devices were primarily in the hands of physicians he perceived to be "stupid" or "charlatans". ${ }^{16(P 231)}$

While Hippocrates is credited with having separated philosophy from medicine, and Osler lightheartedly claimed to be too cheerful to be a philosopher, ${ }^{19}$ Still willingly accepted this description. In calling himself a philosopher, however, Still made it clear that he did not mean philosophy in a dogmatic sense. ${ }^{4(\mathrm{P} 194)}$ Rather, he saw the value of both science and philosophy in medicine. Still considered science to be limited to facts that have been proved objectively, and he asserted that unfortunately there was very little medical science available in his day. He therefore viewed philosophy in medicine as a system used to guide a physician's actions when dealing with the unknown, not as something that prevented change when more knowledge became available. ${ }^{*}$

Still's pragmatic approach to the unknown aspects of medicine by development of philosophic guidelines is not unlike that of Hippocrates, who is said to have realized that practitioners often face problems requiring decisions that cannot wait for future knowledge. ${ }^{17(\mathrm{PPXI}, 56)}$ In that Hippocrates left axioms such as "First do no harm," it may be said that within Still's definition, he did have a medical philosophy. Indeed, it might be argued that in fact Hippocrates separated medicine from theology, not philosophy.

In arriving at patient care decisions, Hippocrates utilized the concept of science as he knew it. The ancient Greeks did not employ experimentation as we now understand it, but instead based their perception of truth upon anecdotal observations 17(PP20,60,69,73): As one distinguished 20th century medical historian noted:

If thirst for information, intelligence, and imagination are the essential ingredients of scientific thinking, the Greeks certainly were striving to be scientific. Our age has added insistence upon verification of observations, of judgements, and of hypothesis and has thus made the experimental method the great tool of modern science. ${ }^{17(P P V I, V I I)}$

It is clear that this same "Hippocratic" concept of science shaped Still's theories. Independent, objective observation was the strength of Hippocratic science, and the ideal to which Still aspired. Hippocrates criticized those who ignored objective observations and blindly followed a set code of ther-

'References 4(pp225,243,394), 8(p10). apy. ${ }^{17(\mathrm{P} 33)}$ Both Osler and Still felt strongly that the polypharmacy that characterized 19th century allopathy constituted such a system, which Still described as "blind guess work"7(P15) and "the nightmare of habit, legalized ignorance, and stupidity."4(P196)

Osler and other progressive physicians of his generation were attempting to change this by incorporating experimentation into the Hippocratic approach to science, and thus, obtaining objective data by which to examine medical practice. Although these efforts eventually were successful, it cannot be said that they had an immediate impact, because until the turn of the century, most published medical information continued to be chiefly anecdotal. ${ }^{5}$

Although Hippocrates' works, like Osler's, contained references to purgatives, laxatives, and bleeding, ${ }^{*}$ if the Adams' book did in fact influence Still, he discounted these therapies based on his 20 years of clinical experience with them. The evidence shows, however, that during his restudy of medicine Still first read available texts and then became heavily engaged in dissection and the study of joints. Seemingly, then, it is plausible that Still read the Adam's translation and was intrigued by the sections on "subluxations" and "partial dislocations" that had perplexed Adams. Then, by inducing motion in the joints of cadavers while observing the associated muscles, nerves, and vasculature, Still rediscovered the meaning and significance of these Hippocratic passages.

\section{Comment}

While the evidence of this theory is only circumstantial, it is extensive enough to warrant mention in the literature. Even if one does not accept this possibility, it would be difficult to argue that Still's theories are not to a large extent consistent with Hippocrates' work, which qualifies him at least as an independent successor in the Hippocratic tradition, along with Osler and others.

In the context of this discussion, however, Still should not be considered to have merely copied Hippocrates, because he contributed many additional observations. These include the interrelationship between nervous and circulatory functions, the anatomic importance of the fascia and lymphatic system, a new explanation of referred pain, and a theory that the body could be stimulated to produce and utilize its own medications. Also, Still's con-

\footnotetext{
'Reference 16(pp80,295,302,316,322-336).
} 
cept of the body as a machine went beyond that of Hippocrates in that he held that any alteration in one part of the structure transmitted stress throughout the entire framework. This dictated the need to manipulatively treat the entire body to fully correct the problem, and, as a practical matter, this approach is what distinguished Still's manipulative treatments from those used by Hippocrates as well as from those of the many manipulative practitioners who preceded him both in America and Europe. 2(PP15-17,29-32)

The fact that Still was advocating beliefs consistent with the Hippocratic tradition and proposed theories which have been subsequently proven leads to the question of why he has not been included in the writing of most medical histories. He was not a graduate of a medical school, but neither were the vast majority of physicians of his or previous generations, nor was graduation from most programs much of an accomplishment prior to the 20 th century. ${ }^{20(\mathrm{PP} 34,41)}$

His writings have been criticized for their rambling style and frequent allegories, yet his books were intended for public consumption, and his style reflected a form of communication common in the Midwest at that time. Indeed, Osler on occasion used parables and allegories to communicate medical information, ${ }^{3(\mathrm{PP} 349,508)}$ and as late as 1938 at least one prominent midwestern physician continued to employ the practice. ${ }^{20(P 46)}$ Still knew that he wrote in allegoric style; indeed, he made a calculated decision to do so. ${ }^{4(\mathrm{P} 164)}$ In addition, unlike Osler, Still did not write chapters consistently or sequentially but rather jotted down paragraphs as his schedule allowed. ${ }^{7\left({ }^{(P 4)}\right.}$ Unfortunately, in the light of modern analysis, this has only emphasized his eccentricities.

These factors, however, probably played only a small role in the lack of recognition by traditional historians. More likely, it stems from Still's unapologetic and complete break with the medical establishment of his day. While previous medical reformers had proposed dramatic changes, even the most extreme attempted to follow a course within the fringes of the framework of medical laws and practice. Still could have taken this approach but chose not to.

His strong feelings on breaking away from the medical establishment without any animosity toward its individual members might be explained by the heavy influence that his abolitionist and Civil War experiences had on his concept of honorable conflict resolution. His writings frequently utilized military symbolism to explain his theories and beliefs. If he saw conflict in these Civil War terms, blue $v$ gray engaged on an open field of battle, it is not difficult to understand why this physician, who had been totally rejected by most of his colleagues, felt that setting his students apart from others was the honorable course to follow in the debate over the future direction of medicine.

Osler, on the other hand, did not encounter rejection, merely disagreement, and he was given a prominent place within the establishment from which he could advocate reform. It was not his intensity but rather his ability to change the system from within that differentiated him from Still. He rejected as "useless" all medical clinics of $1890,{ }^{3(\mathrm{P} 266)}$ and, in 1901, he told the New York Sun:

The New School of Medicine is one with firm faith in a few good, well tried drugs, little or none in the great mass of medicines now in use- a new school which cares nothing for homeopathy, and less so for so-called allopathy, but seeks to study rationally and scientifically the action of drugs old and new. ${ }^{3(\mathrm{P} 546)}$

As a reformer, Osler found himself frequently at odds with the leadership of both the American and British medical associations, usually in defense of other physicians whom he thought were victims of organized medical oppression.* Unfortunately, there appear to be no durable references of Osler commenting on Still's theories, even though he was within 150 miles of Still when he spoke at a St. Louis conference in $1902 .^{3(\mathrm{P} 592)}$ To examine what his attitude might have been, however, we can look to his public statements on other alternative schools:

We cannot, however, escape from the important fact that in the eyes of the law we shall all stand equal, and if we wish legislation for the protection of the public we have got to ask for it together, not singly.... When we think of the nine or ten subjects which we have in common, we may surely, in the interests of the public, bury animosities and agree to differ on the question of therapeutics. ${ }^{3(307)}$

On parochialism in medicine, Osler said, "It easily degenerates into a base intolerance which looks with disdain on men of other schools and other ways....There is plenty of room for honest and friendly rivalry between schools and hospitals."3(P587)

Most other physicians did not share Osler's tolerant views, however; as a result, mainstream medicine's attitude toward Still was alternately to oppose or ignore him, believing that by ignoring his movement they might cause it to disappear. Unfortunately, the biases of that generation have left an historical gap.

\footnotetext{
*References 3(pp255,307,587), 9(112).
} 


\section{Conclusions}

Recognition of the inadequacies of 19th century medicine is what led Osler and Still to advocate reform, and the variable levels of resistance that they encountered were only functions of their perceived threat to the status quo. William Osler, although a reformer, was allowed to become part of the medical establishment, while Andrew Taylor Still was not.

As a result, the impact of these physicians has been felt in different ways. Still gave up any hope of changing the existing medical system and took his theories to the public and to individual physicians who expressed an interest in them. His impact, therefore, was limited to a lesser number of people initially, but it was immediate and extensive to those it did affect. Any discussion of how the existence of osteopathic schools has influenced the medical profession as a whole is beyond the scope of this paper. However, by opening a school, Still established a legacy of thought that could be transmitted through the years to an expanding number of future physicians.

Osler, on the other hand, attempted to exert influence on the entire medical profession. Although there is no doubt that he saw significant changes occur during his lifetime, it would be incorrect to say that his impact on the average physician was overwhelming. Rather, like Still, it was on his students and their successors. As the number of Osler's followers has expanded, so has the impact of his thoughts on medical practice, which now holds mainstream attitudes that would seem quite compatible with Osler's and, by association, with Still's, because Osler and Still held many common beliefs.

It is important for the medical historian to realize that Still did not reject medicine as it exists today, but, like Osler, he rejected medicine as it was practiced in the 19 th century. Given what we now know, wouldn't present day physicians wish to believe that they would have come to the same conclusions if they had practiced in that time, and that they would have counted themselves among the reformers? Could any of us honestly say that if after making these observations we were, like Still, ostracized by our colleagues, would we not have at least considered following a course similar to the one that he did?

It is commonly accepted that Hippocratic influence was lost during the Middle Ages following the end of the Greco-Roman period and that practice changed very little preceding this one. ${ }^{18(\mathrm{PP} 27,117,138-140)}$

The contention that Osler was heavily influenced by Hippocrates has never been challenged, and while the theory that Still was similarly influenced may be controversial, there is a considerable amount of evidence that demonstrates that his ideas were consistent with Hippocratic teachings.

By exercising leadership and advocating reform during one of the most dynamic periods in the history of medicine, these two great physicians exerted influences that resulted in significant and lasting impacts on their respective schools. In that the teachings of both William Osler and Andrew Taylor Still are to a large extent consistent with those of Hippocrates, the view that American medicine today reflects the influence of these two men also can be seen as a belated return to and rebirth of Hippocratic thought in medicine.

1. McConnell, CP: The Practice of Osteopathy. Chicago, The Hammond Press, 1899.

2. Gevitz N: The D.O.'s: Osteopathic Medicine in America. Baltimore, The Johns Hopkins University Press, 1982.

3. Cushing H: The Life of Sir William Osler. Oxford, England, Oxford University Press, 1925, vol 1.

4. Still AT: Autobiography of Andrew T. Still. the author, Kirksville, Mo, the author, 1897

5. Osler W: The Principles and Practice of Medicine. New York, D Appleton and $\mathrm{Co}, 1892$.

6. Walter GA: Osteopathic Medicine: Past and Present. Kirksville, Mo, Kirksville College of Osteopathic Medicine, 1981.

7. Still AT: Philosophy of Osteopathy. Kirksville, Mo, the author, 1899. 8. Still AT: Osteopathy Research and Practice. Kirksville, Mo, the author, 1910.

9. Cushing H: The Life of Sir William Osler. Oxford, England, Oxford University Press, 1925, vol. 2.

10. Girard DE: The History of Osler's Principles and Practice of Medicine. Res Staff Phys 1981;97-103.

11. Edelstein L: William Osler's philosophy. Bull Hist Med 1946;20:270293.

12. Holly HL: A Continual Remembrance. Springfield, Ill, Charles C Thomas, 1968 , pp 3,43

13. Osler, W: The Principles and Practice of Medicine, ed 8. New York, D Appleton and $\mathrm{Co}, 1912$.

14. Proceedings of the Thirteenth Annual AOA Research Conference, 1986: Part I. JAOA 86;9:592-608.

15. Proceedings of the Thirteenth Annual AOA Research Conference, 1986: Part II. JAOA 86;10:663-689.

16. Adams F (trans): The Genuine Works of Hippocrates. London, Sydenham Society in England, 1849 (reprinted Huntington, NY, Robert E. Krieger Publishing Co, 1972).

17. Heidel WA: Hippocratic Medicine: Its Spirit and Method. New York, Columbia University Press, 1941 (reprinted 1981).

18. Moon RO: Hippocrates and His Successors in Relation to the Philosophy of Their Time. London, Longmans, Greens, and Co, 1923.

19. The medical man as a philosopher: An examination of the pragmatism of William Osler. Bull Hist Med 1964;38:199-225.

20. Hertzler AE: The Horse and Buggy Doctor. Lincoln, Neb, University of Nebraska Press, 1938.

Mr. Suter is a fourth-year student at the University of Osteopathic Medicine and Health Sciences, Des Moines, Iowa.

Reprint requests to Mr Suter, University of Osteopathic Medicine and Health Sciences, 3200 Grand Ave, Des Moines, IA 50312. 